\title{
ENRAIZAMENTO DE MINIESTACA CAULINAR E FOLIAR NA PROPAGAÇÃO VEGETATIVA DE CEDRO-ROSA (Cedrela fissilis Vell.) ${ }^{1}$
}

\author{
Aloisio Xavier², Glêison Augusto dos Santos ${ }^{3}$ e Marcelo Lelis de Oliveira ${ }^{3}$
}

\begin{abstract}
RESUMO - No presente trabalho objetivou-se avaliar o enraizamento de cinco diferentes tipos de miniestaca (caulinar, caulinar apical, caulinar intermediária, caulinar apical desfolhada e foliar), na propagação vegetativa de cedro-rosa (Cedrela fissilis) por miniestaquia, a partir de material seminal. Os resultados obtidos quanto ao enraizamento indicaram o melhor desempenho da miniestaca caulinar, com $84 \%$ de sobrevivência das mudas aos 90 dias de idade, demonstrando o potencial da miniestaquia como alternativa na produção de mudas de cedrorosa.
\end{abstract}

Palavras-chave: Estaquia, miniestaquia, propagação vegetativa e clonagem.

\section{ROOTING OF STEM AND LEAF MINICUTTINGS IN THE VEGETATIVE PROPAGATION OF CEDRO-ROSA (Cedrela fissilis Vell.)}

\begin{abstract}
This work aimed to evaluate the rooting of five different types of minicuttings (stem, apical stem, intermediate stem, apical stem with removed leaves and leaf), in the vegetative propagation of cedro-rosa (Cedrela fissilis), by applying the minicutting technique, using seedlings material. The results showed that stem cutting was the most efficient technique for the vegetative propagation of this species, with up to $84 \%$ survival at 90 days of age. Thus, this technique can be used as an alternative in the production of minicuttings of this species, throughout the year.
\end{abstract}

Key words: Cutting, minicutting technique, vegetative propagation and cloning.

\section{INTRODUÇÃO}

A espécie cedro-rosa (Cedrela fissilis) é encontrada desde o Rio Grande do Sul até Minas Gerais, principalmente nas florestas semidecídua e pluvial atlântica, ocorrendo também em menor intensidade nas outras regiões do País (Lorenzi, 1998). Sua utilização principal tem sido nas marcenarias e na construção naval e aeronáutica, o que a torna uma das espécies nativas de maior importância econômica para o Brasil.

Ao longo dos anos, sua exploração foi realizada de maneira extrativista, havendo carência de informações sobre processos que viabilizem o seu plantio em programas de reconstituição e, ou, plantios para fins comerciais.

Na silvicultura brasileira, a qualidade da muda usada nos plantios comerciais influencia o sucesso de qualquer programa de desenvolvimento florestal, que para algumas espécies já existem conhecimento científico e experiências suficientes na implementação do processo produtivo. No entanto, as informações técnicas disponíveis sobre a produção de mudas de cedro-rosa são escassas, o que limita o progresso de sua silvicultura.

Relatos iniciais de Santos et al. (2000a) destacam a miniestaquia como uma técnica promissora para produção

1 Recebido para publicação em 18.12.2001.

Aceito para publicação em 12.5.2003.

2 Professor do Dep. de Engenharia Florestal da Universidade Federal de Viçosa - UFV, 36571-000 Viçosa-MG, ${ }^{3}$ Mestrando em Ciência Florestal, Dep. de Engenharia Florestal da UFV. 
de mudas clonais dessa espécie. Segundo os autores, a aplicabilidade da miniestaquia em espécies nativas está no fato de ser uma opção para a propagação vegetativa de certas espécies que têm a semente como insumo limitante, com dificuldade de germinação e armazenamento, bem como é uma ferramenta de clonagem que visa a maximização da qualidade e uniformidade da muda plantada.

A aplicação da miniestaquia na propagação clonal de Eucalyptus é uma realidade e mostra-se bem desenvolvida (Xavier et al., 2001), entretanto em espécies florestais nativas ainda é recente, precisando de desenvolvimento quanto aos ajustes no processo de produção da muda. O tipo de propágulo utilizado para o enraizamento das miniestacas, por exemplo, é um dos itens importantes a ser avaliado na definição da melhor forma de propagação vegetativa.

Dentre os tipos de propágulos geralmente utilizados na propagação vegetativa estão as estacas, que podem ser caulinar, foliar ou radicular. A propagação por estaca caulinar, geralmente, requer apenas que um novo sistema radicular adventício seja formado, dado ao potencial da regeneração de gemas pré-formadas já existente. Entretanto, nas estacas foliar e radicular há a necessidade de formação adventícia tanto do sistema radicular como da parte aérea, o que dificulta a sua utilização na área florestal.

A estaca caulinar é constituída por segmento de um ramo com gemas apicais e, ou, laterais, podendo ser lenhosa ou herbácea. Segundo Hartmann et al. (1997), no caso de a estaca caulinar lenhosa apresentar maior grau de lignificação, esta é menos perecível, facilitando o seu manuseio e transporte. Já a estaca caulinar herbácea demanda maior controle ambiental no viveiro, entretanto possui maior potencial de enraizamento (Browse, 1979), sendo este tipo de estaca utilizado na propagação vegetativa por miniestaquia de Eucalyptus.

A estaca foliar tem sido utilizada com maior freqüência na floricultura e jardinagem, ainda sendo pouco estudada na silvicultura. A maioria das estacas de folhas enraíza facilmente, porém com certa limitação para regeneração e desenvolvimento da parte aérea (Hartmann et al., 1997). Em relação à estaca radicular, em geral a sua utilização é restrita na propagação vegetativa de espécies florestais (Gomes, 1987; Hartmann et al.,1997).

Diante dessa diversidade de respostas apresentadas pelos tipos de estacas, o objetivo deste trabalho foi avaliar o desempenho de miniestaca caulinar e foliar na propagação vegetativa de cedro-rosa (Cedrela fissilis), a partir de material seminal, quanto à sobrevivência e capacidade produtiva das minicepas e no enraizamento e na sobrevivência das miniestacas e em seu crescimento vegetativo em altura e diâmetro do colo.

\section{MATERIAL E MÉTODOS}

O presente estudo foi realizado no Viveiro de Pesquisas Florestais do Departamento de Engenharia Florestal, da Universidade Federal de Viçosa, Viçosa, Minas Gerais.

O material genético/vegetativo inicialmente utilizado foi originado de mudas de cedro-rosa (Cedrela fissilis) produzidas a partir de sementes, em tubetes plásticos de $55 \mathrm{~cm}^{3}$, contendo substrato formado pela mistura de composto orgânico (80\%) e moinha de carvão moída (20\%). Ao atingirem uma altura média de $15 \mathrm{~cm}$, as mudas foram transferidas para casa de sombra com $50 \%$ de sombreamento, sendo, em seguida, promovida de cepa da parte apical, a uma altura de $10 \mathrm{~cm}$ da base, visando estimular a ocorrência de brotações laterais, constituindo as minicepas para formação do jardim miniclonal.

O manejo do jardim miniclonal constituiu-se, principalmente, de irrigações diárias e fertilizações com macro e micronutrientes, visando manter o turgor hídrico e o status nutricional adequado das minicepas para produção de material vegetativo (miniestacas).

A coleta das miniestacas realizou-se após 30 dias da decepa das minicepas (Figura 1A), quando estas apresentavam tamanho suficiente em função dos diferentes tipos de estacas (Figura 1B) utilizados no presente estudo.

Com base na Figura 1B, os tipos de miniestacas avaliados no presente estudo foram definidos como: (1) caulinar; (2) caulinar apical; (3) caulinar intermediária; (4) caulinar apical desfolhada; e (5) foliar.

As miniestacas, imediatamente após serem coletadas e preparadas, conforme o tipo a ser testado, foram acondicionadas em caixas de isopor contendo água. Para o enraizamento, estas foram estaqueadas, sem aplicação de reguladores de crescimento, em casa de vegetação com temperatura entre 25 e $30{ }^{\circ} \mathrm{C}$ e umidade controlada (> 80\%). O recipiente utilizado foi tubete plástico de $55 \mathrm{~cm}^{3}$ e o substrato foi constituído pela mistura de vermiculita de granulometria média $(50 \%)$ e palha de arroz carbonizada (50\%), com a adição de fertilizantes $\mathrm{N}: \mathrm{P}: \mathrm{K}(8: 32: 16)$. 


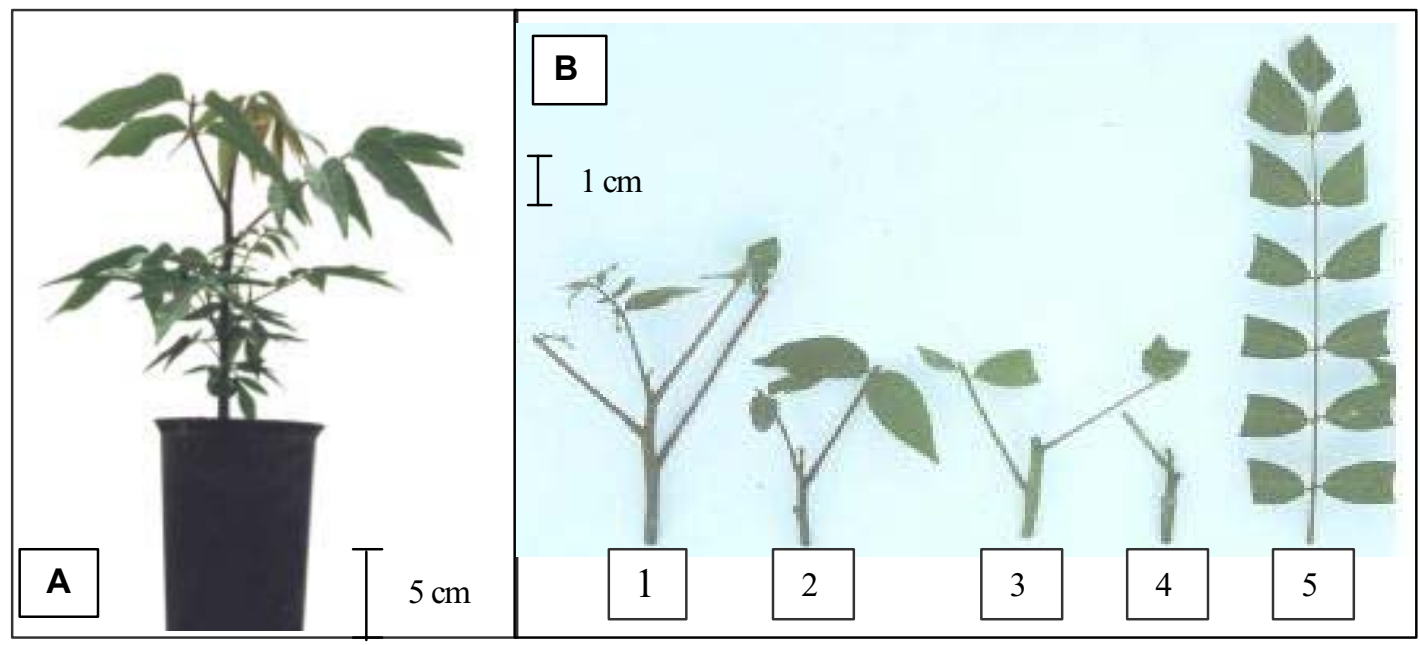

Figura 1 - (A) Minicepa e (B) tipo de miniestaca de cedro-rosa (Cedrela fissilis) utilizados no presente estudo: (1) caulinar, (2) caulinar apical, (3) caulinar intermediária, (4) caulinar apical desfolhada e (5) foliar.

Figure 1 - (A) Cedro-rosa (Cedrela fissilis) ministumps and (B) type of minicuttings: (1) stem, (2) apical stem, (3) intermediate stem, (4) apical stem with removed leaves and (5) leaf.

O período de permanência em casa de vegetação para indução do enraizamento foi de 30 dias, sendo, as miniestacas, em seguida, transferidas para aclimatação em casa de sombra (sombreamento de $50 \%$ ) por sete dias $\mathrm{e}$, posteriormente, transferidas para crescimento em área aberta, com $25 \%$ de sombreamento, onde receberam fertilização de macro e micronutrientes $(0,05 \mathrm{~g} /$ planta, uma vez por semana).

As avaliações realizadas constituíram-se da produção de miniestacas/minicepa/coleta, de acordo com o tipo de miniestaca utilizado; da sobrevivência das miniestacas na saída da casa de vegetação; do porcentual de enraizamento na saída da casa de sombra; da sobrevivência das mudas aos 60 e 90 dias de idade; e do crescimento em altura e diâmetro do colo das mudas aos 90 dias de idade.

O delineamento experimental utilizado foi o inteiramente casualizado, constituído por cinco tratamentos (tipos de miniestacas), com quatro repetições e oito plantas por parcela. Os resultados obtidos foram submetidos à análise de variância e os dados foram discriminados pelo teste de Duncan, a 5\% de probabilidade.

\section{RESULTADOS E DISCUSSÕES}

Os resultados observados para produção de miniestacas/minicepa/coleta variaram de 1,0 a 1,3 para as miniestacas caulinares, enquanto a miniestaca foliar apresentou valores de 4 miniestacas/minicepa/coleta. Para o primeiro caso, os valores encontrados para produção de miniestacas caulinares/minicepa/coleta concordam com os obtidos para mogno e sete-cascas, conforme citado por Santos et al. (2000b). A menor produtividade obtida para as miniestacas caulinares, em relação à estaca foliar, é decorrente da filotaxia apresentada pelas espécies de folhas compostas, o que dificulta a obtenção de maior produtividade para este tipo de estaca.

Com relação à sobrevivência das minicepas, não foi observada nenhuma mortalidade durante o período da experimentação, o que evidencia a sustentabilidade do sistema de jardim miniclonal utilizado neste estudo. Estes resultados indicam o potencial do cedro-rosa quanto à regeneração vegetativa das minicepas, em função das coletas sucessivas de miniestacas, permitindo a adoção da miniestaquia como alternativa potencial na propagação desta espécie. Além disto, a técnica adotada permite um planejamento mais adequado, visando atender a uma determinada demanda nas diferentes épocas do ano, estruturas e condições ambientais variadas.

Com relação às avaliações de enraizamento das miniestacas, de acordo com os resultados da análise de variância apresentados no Quadro 1, observam-se efeitos significativos no que tange a todas as características avaliadas (com exceção da sobrevivência na saída da casa de vegetação) entre os cinco diferentes tipos de estaca utilizados.

R. Árvore, Viçosa-MG, v.27, n.3, p.351-356, 2003 
Quadro 1 - Resultados da análise de variância das características de sobrevivência na saída da casa de vegetação (SOBCV), enraizamento na saída da casa de sombra (SOBCS), sobrevivência aos 60 dias (SOB60), sobrevivência aos 90 dias (SOB90) e altura (ALT) e diâmetro do colo (DC) das mudas de cedro-rosa (Cedrela fissilis), em função dos diferentes tipos de miniestacas utilizados

Table 1 - Analysis of variance of the survival at greenhouse exit (SOBSCV); rooting at shade house exit (SOBCS); survival at 60 (SOB60) and 90 (SOB90) days of age, height (ALT) and root collar diameter (DC), ) as a result of different types of minicuttings (type 1, 2, 3, 4 and 5) of cedro-rosa (Cedrela fissilis)

\begin{tabular}{|l|c|c|c|c|c|c|c|}
\hline \multicolumn{1}{|c|}{} & \multicolumn{9}{|c|}{ Quadrados Médios } \\
\hline FV & G.L. & $\begin{array}{c}\text { SOBCV } \\
(\%)\end{array}$ & $\begin{array}{c}\text { SOBCS } \\
(\%)\end{array}$ & $\begin{array}{c}\text { SOB60 } \\
(\%)\end{array}$ & $\begin{array}{c}\text { SOB90 } \\
(\%)\end{array}$ & $\begin{array}{c}\text { ALT } \\
(\mathrm{cm})\end{array}$ & $\begin{array}{c}\text { DC } \\
(\mathrm{mm})\end{array}$ \\
\hline Tipo de Estaca & 4 & $402,3^{\text {ns }}$ & $3.234,3^{*}$ & $3.445,3^{*}$ & $5.808,5^{*}$ & $138,5^{*}$ & $8,9^{*}$ \\
Resíduo & 15 & 161,4 & 145,8 & 156,2 & 192,7 & 1,7 & 0,07 \\
\hline Média Geral & & 88,7 & 70,0 & 65,0 & 52,5 & 10,3 & 2,6 \\
CV $_{\text {exp. (\%) }}$ & & 14,3 & 17,2 & 19,2 & 26,4 & 12,8 & 10,0 \\
\hline
\end{tabular}

$* \mathrm{e}^{\mathrm{ns}}$ significativo e não-significativo, respectivamente, pelo teste de $\mathrm{F}$, a $5 \%$ de probabilidade.

(A)

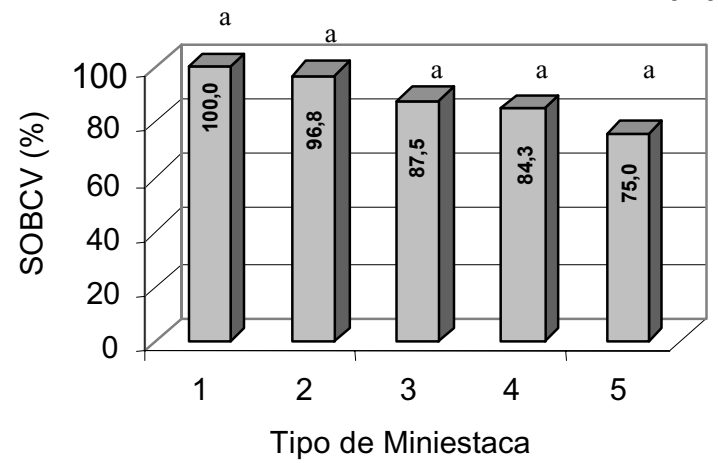

(C)

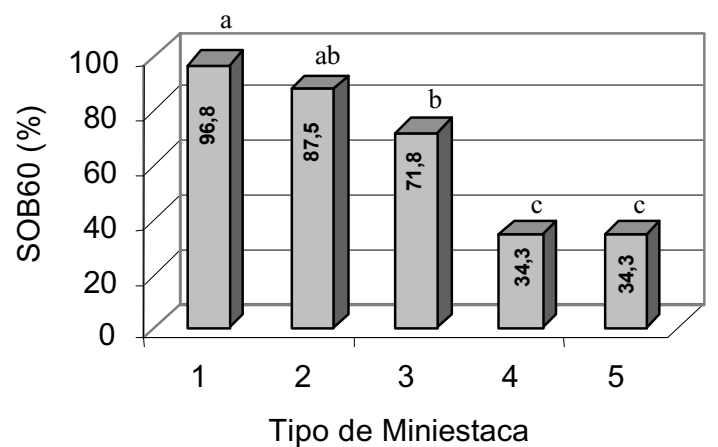

(B)

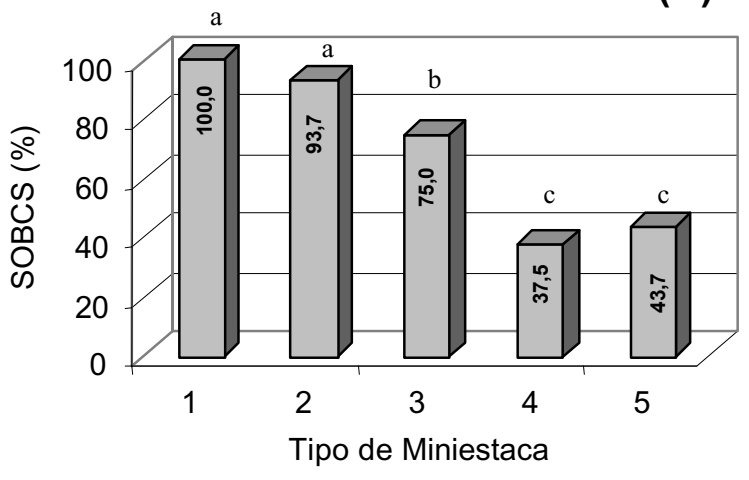

(D)

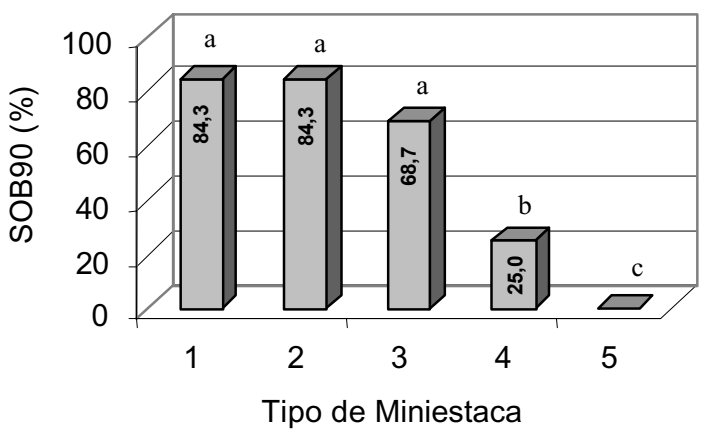

Figura 2 - Enraizamento das miniestacas de cedro-rosa (Cedrela fissilis) em função dos diferentes tipos de miniestacas (1-caulinar; 2- caulinar apical; 3- caulinar intermediária; 4- caulinar apical desfolhada; e 5- foliar). (A) sobrevivência das miniestacas na saída da casa de vegetação (SOBCV); (B) enraizamento das miniestacas na saída da casa de sombra (SOBCS); (C) sobrevivência das miniestacas aos 60 dias de idade (SOB60); e (D) sobrevivência das miniestacas aos 90 dias de idade (SOB90). As médias seguidas pela mesma letra não diferem entre si pelo teste de Duncan, a 5\% de probabilidade.

Figure 2 - Rooting of the minicuttings of cedro-rosa (Cedrela fissilis) at the greenhouse exit (A), shade house exit (B) and minicutting survival at $60(C)$ and 90 days of age (D) as a result of different types of minicuttings (1: stem, 2: apical stem, 3: intermediate stem, 4: apical stem with removed leaves; 5: leaf). Averages followed by the same letter do not differ by the Duncan test, at $5 \%$ probability.

R. Árvore, Viçosa-MG, v.27, n.3, p.351-356, 2003 
$\mathrm{Na}$ avaliação da sobrevivência das miniestacas, na saída da casa de vegetação, os tipos de estacas não apresentaram diferenças significativas (Figura 2A), o que indica a adequação e o controle do ambiente de casa de vegetação utilizado na manutenção da sobrevivência dos propágulos vegetativos de cedro-rosa. Embora essa sobrevivência na casa de vegetação não seja uma garantia de seu posterior enraizamento, segundo Iritani \& Soares (1983), esse é o principal fator para se alcançar tal objetivo, uma vez que as condições adequadas de umidade e temperatura garantem o turgor hídrico das estacas, além da não-manifestação de agentes patogênicos.

Para o enraizamento na saída da casa de sombra (Figura 2B), observa-se a superioridade de enraizamento para a estaca caulinar, principalmente para os tipos $1 \mathrm{e}$ 2. Provavelmente, esta superioridade seja devido à presença de folha e ao fato de a síntese de auxinas indutoras do processo de enraizamento ser produzida principalmente no ápice caulinar, proporcionando, em um primeiro momento, maior potencial de enraizamento (Figura 3A).

Quanto à estaca caulinar apical desfolhada (tipo 4), a ausência de folhas é um fator importante no processo de enraizamento. Segundo Wilson (1994), a presença da folha na estaca é de fundamental importância para o processo de enraizamento, o que se deve a algumas substâncias, como os carboidratos produzidos durante a fotossíntese e, principalmente, a produção das auxinas responsáveis pelos efeitos correlatos no enraizamento adventício (Hartmann et al., 1997).

$\mathrm{Na}$ comparação da sobrevivência das mudas aos 60 dias (Figura 2C) com a sobrevivência das mudas aos 90 dias de idade (Figura 2D), ressalta-se a total mortalidade ocorrida com a estaca foliar. Observou-se neste tipo de estaca que não houve nenhuma resposta ao desenvolvimento e crescimento da parte aérea, indicando a incompetência dos tecidos vegetais em desenvolver novos meristemas caulinares (Figura 3B), o que concorda com Hartmann et al. (1997), que afirmam ser esta uma das limitações do uso da estaca foliar para algumas espécies florestais.

Na sobrevivência aos 90 dias de idade (Figura 2D), nota-se ainda um decréscimo na sobrevivência da estaca caulinar (tipo 1) e da estaca caulinar apical (tipo 2), fazendo com que não mais ocorram diferenças significativas entre esses dois tipos de estaca e a estaca caulinar intermediária (tipo 3), o que pode ser atribuído ao fato de os dois primeiros tipos de estaca serem mais sensíveis aos efeitos adversos do ambiente, enquanto a estaca caulinar intermediária, por tratar-se de um material mais rústico e lignificado, possui maior resistência às variações ambientais das condições de pleno sol, apresentando resultados finais semelhantes aos tipos de estacas 1 e 2 .

Com base neste resultado, o efeito ambiental na área de pleno sol influenciou a sobrevivência dos diferentes tipos de estaca, durante a rustificação das mudas, o que indica que na propagação desta espécie deve-se optar-se pelo tipo de estaca que melhor se adaptar às condições climáticas do local da produção destas mudas.
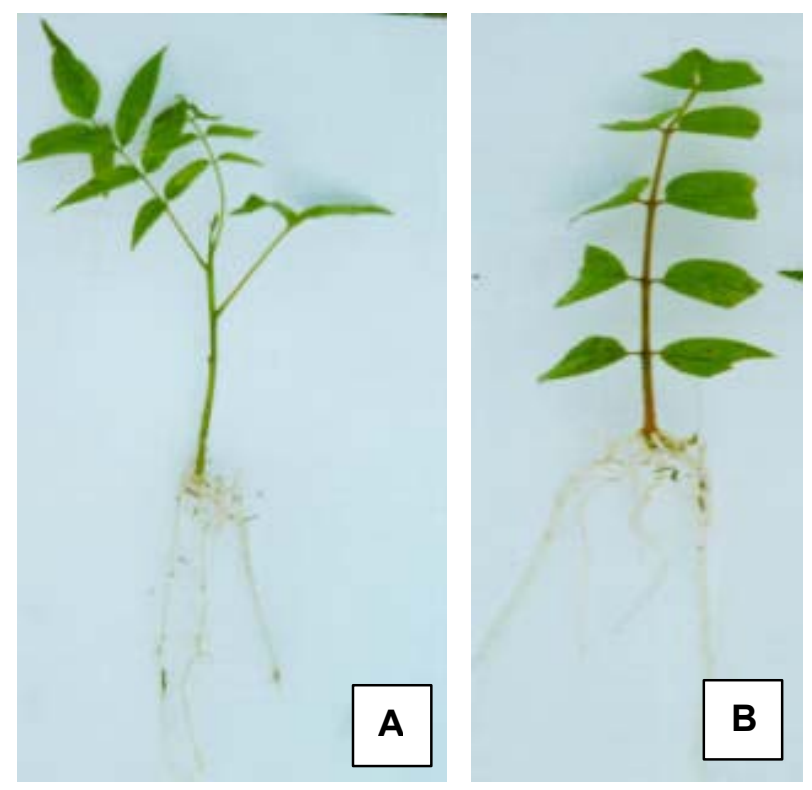

Figura 3 - Muda de cedro-rosa (Cedrela fissilis) produzida a partir do enraizamento de miniestaca caulinar apical (A) e miniestaca foliar (B), aos 60 dias de idade.

Figure 3-Cedro-rosa (Cedrela fissilis) seedling produced by rooting of apical minicutting $(A)$ and leaf minicutting (B), at 60 days of age.

Os resultados para altura e diâmetro do colo (Quadro 2) confirmam o melhor desempenho apresentado pela estaca caulinar (tipo 1), estaca caulinar apical (tipo 2) e estaca caulinar intermediária (tipo 3 ) em relação aos demais tratamentos, indicando a sua habilidade em promover, além do enraizamento, um bom crescimento vegetativo das mudas produzidas através da técnica de miniestaquia.

R. Árvore, Viçosa-MG, v.27, n.3, p.351-356, 2003 
Quadro 2 - Crescimento em altura (ALT90) e diâmetro do colo (DC90) das mudas de cedro-rosa (Cedrela fissilis) aos 90 dias de idade, em função dos diferentes tipos de miniestaca (1- caulinar; 2 - caulinar apical; 3 - caulinar intermediária; 4-caulinar apical desfolhada; e 5-foliar). As médias seguidas pela mesma letra na linha não diferem entre si pelo teste de Duncan, a $5 \%$ de probabilidade

Table 2 - Height (ALT90) and root collar diameter (DC90) of the minicuttings of cedro-rosa (Cedrela fissilis) at 90 days of age, as a result of different types of minicuttings (1: stem, 2: apical stem, 3: intermediate stem, 4: apical stem with removed leaves; 5 : leaf). Averages followed by the same letter do not differ by the Duncan test, at $5 \%$ probability

\begin{tabular}{|l|c|c|c|c|c|}
\hline \multirow{2}{*}{ Característica } & \multicolumn{5}{|c|}{ Tipo de Estaca } \\
\cline { 2 - 7 } & 1 & 2 & 3 & 4 & 5 \\
\hline ALT90 $(\mathrm{cm})$ & $13,9 \mathrm{a}$ & $13,9 \mathrm{a}$ & $12,6 \mathrm{ab}$ & $11,2 \mathrm{~b}$ & - \\
DC90 $(\mathrm{mm})$ & $3,2 \mathrm{a}$ & $3,5 \mathrm{a}$ & $3,2 \mathrm{a}$ & $3,3 \mathrm{a}$ & - \\
\hline
\end{tabular}

\section{CONCLUSÕES}

Diante dos resultados encontrados neste trabalho, conclui-se que a miniestaca caulinar com folhas mostrouse mais adequada à propagação vegetativa de cedro-rosa (Cedrela fissilis) por miniestaquia, a partir de material seminal. Além disto, em função dos altos porcentuais de enraizamento obtido pelas miniestacas caulinares, a miniestaquia de cedro-rosa, a partir de material de origem seminal, indica ser tecnicamente viável, tornando-se uma alternativa para produção de mudas dessa espécie durante todo o ano, principalmente nas situações em que a semente é insumo limitante.

\section{AGRADECIMENTO}

Ao Programa de Bolsas de Iniciação Científica do CNPq (PIBIC/UFV), pela concessão da bolsa ao estudante G. A. S., e ao Grupo de Pesquisa e Desenvolvimento em Silvicultura Clonal do DEF/UFV, pela oportunidade de trabalho conjunto.

\section{REFERÊNCIAS BIBLIOGRÁFICAS}

BROWSE, P. M. A propagação das plantas. Lisboa: Europa-América, 1979. 229 p.

GOMES, A. L. Propagação clonal: princípios e particularidades. Vila Real: Universidade de Trás-os Montes e Alto Douro, 1987. 67 p. (série Didáctica, Ciências Aplicadas, 1).

HARTMANN, H. T. et al. Plant Propagation: principles and practices. 6.ed. New Jersey: Prentice-Hall, 1997. $770 \mathrm{p}$.

IRITANI, C.; SOARES, R. V. Indução do enraizamento de estacas de Araucaria angustifolia através da aplicação de reguladores de crescimento. In: CONGRESSO FLORESTAL BRASILEIRO, 4., 1982, Belo Horizonte. Anais... Belo Horizonte: SBS, 1983. p. 313-317.

LORENZI, H. Árvores Brasileiras: manual de identificação e cultivo de plantas arbóreas nativas do Brasil. 2.ed. Nova Odessa: Plantarum, 1998. 368 p.

SANTOS, G. A. et al. Uso da miniestaquia na propagação clonal de Cedrela fissilis (Cedro-Rosa). In: CONGRESSO E EXPOSIÇÃO INTERNACIONAL SOBRE FLORESTAS, 6., 2000, Porto Seguro. Resumos Técnicos... Rio de Janeiro: Instituto Ambiental Biosfera, 2000a. p. 203.

SANTOS, G. A. et al. Enraizamento de miniestacas de Jequitibá rosa, Sete Cascas e Mogno - (Resultados Preliminares). In: SIMPÓSIO DE INICIAÇÃO CIENTÍFICA, 10., 2000, Viçosa. Anais... Viçosa, MG: Universidade Federal de Viçosa, 2000b. p.63.

WILSON, P. J. Contributions of the leaves and axilary shoots to rooting in Eucalyptus grandis stem cuttings. Journal of Horticultural Science, v. 69, p. 999-1007, 1994.

XAVIER, A. et al. Desempenho do enraizamento de microestacas e miniestacas de clones híbridos de Eucalyptus grandis. Revista Árvore, v. 25, n. 4, 403-411, 2001. 